\title{
Study On Photovoltaic Modules On Greenhouse Roof For Energy And Strawberry Production
}

\author{
Yilian Tang, Ming $\mathrm{Li}^{*}$ and Xun Ma \\ Solar Energy Research Institute, Yunnan Normal University, Kunming 650500, China
}

\begin{abstract}
The aim of this study was to investigate the effect of PV modules mounted on top of a greenhouse, on the growth of strawberries and microclimate conditions as well as to estimate the generated energy. In this study, two greenhouses with the same volume were established. One greenhouse was equipped with the opaque photovoltaic (OPV) modules which accounted for $25.9 \%$ of the roof area, and the other was equipped with the semi-transparent photovoltaic (STPV) modules which accounted for $20 \%$ of the roof area. The maximum annual power generation of OPV and STPV modules was 880 and $388 \mathrm{kWh}$ with $30^{\circ}$ tilt angle, respectively, by simulating different tilt angles. The temperature under the OPV and STPV modules was 2.9 and $1.1{ }^{\circ} \mathrm{C}$ lower than the unshaded part in the greenhouses, respectively, at noon in clear weather, and had little effect on relative humidity. The photosynthetically active radiation (PAR) under OPV and STPV modules was reduced by $43.5 \%$ and $31.7 \%$, respectively, under the PE film greenhouse. The contents of soluble solids in strawberries in OPV and STPV greenhouses were 16.4 and $15.7 \mathrm{mg} / \mathrm{g}$ respectively, which were higher than those in unshaded samples. The quality and yield of the strawberry samples under the shade of OPV were better than those of the STPV shade.
\end{abstract}

\section{Introduction}

The photovoltaic (PV) modules installed on the roof of greenhouse can not only generate electricity, but also reduce the solar radiation through the roof, and fall to the plants in the greenhouse, affecting their light, thus affecting crop growth [1]. PV power generation can meet greenhouse energy demand in cooling, heating, ventilation, artificial lighting and other energy needs [2]. The energy generated by PV modules with different tilt angles and installations has different effects on the greenhouse microclimate, so that information that can be used to support farmers and create PV greenhouses can generate income from electrical and agricultural activities. [3-7]. Generally, opaque or semi-transparent polysilicon or monocrystalline silicon PV panels are integrated on the south-facing roof of the greenhouse [811]. The shading of PV modules affects the solar radiation entering the greenhouse $[7,12,13]$, and affects the temperature, humidity and light in the greenhouse [14-17]. However, temperature and light strongly interact and affect plant growth [18]. Environmental control of greenhouses during the summer is one of the main challenges in tropical and subtropical climates. Shading is an effective way to reduce light transmission [19], furthermore, shading agricultural greenhouses and cooling systems in hot and sunny areas can reduce water consumption by $25 \%$, reduce greenhouse temperature to $5-10{ }^{\circ} \mathrm{C}$ below outdoor temperature, and increase relative humidity by $15-20 \%$. In addition, shading reduces solar radiation by $30-50 \%$ and cooling energy consumption by $20 \%$ and $15 \%[20]$.

Strawberry (Fragaria $\mathrm{x}$ ananassa) is a delicious and healthy fruit, loved by people all over the world [21, 22]. The growth of strawberries in greenhouses is a widespread cultivation method that prevents damage from natural disasters and provides a suitable environment for strawberry growth [23, 24]. Strawberry has obvious response to the change of growing environment especially temperature and light have significant influence on strawberry production [25-27]. In recent years, some scholars have studied the effects of $20 \%$ roof power generation of photovoltaic modules and shading on plant growth $[1,16]$. However, there are few studies on strawberry planting in PV greenhouses, especially the research on the influence of shading of PV modules on the growth environment and strawberry production. Therefore, the purpose of this study is to find out the electrical energy generated by opaque polycrystalline silicon PV module and translucent monocrystalline silicon PV module at different inclination angles and the environmental parameters in greenhouses, and the influence of shading on strawberry production in greenhouses under different placement modes of PVmodules.

\footnotetext{
* Corresponding author: Ming Li $\underline{1 m l 11 d y @ 126 . c o m}$
} 


\section{Materials and methods}

\subsection{Construction of greenhouses and configuration of PV Modules}

This experiment was built in Kunming, China (102.68 E longitude and $25.07^{\circ} \mathrm{N}$ latitude). Two east-west greenhouses were installed on the roof of the solar energy research institute building. As shown in Fig. 1, the two greenhouses had the same size, $7.5 \mathrm{~m}$ long and $3.5 \mathrm{~m}$ wide, covering an area of $26.25 \mathrm{~m}^{2}$ and $78.75 \mathrm{~m}^{3}$ in volume. The greenhouse roof was covered with a layer of $0.12 \mathrm{~mm}$ polyethylene (PE) film. The opaque photovoltaic (OPV) modules and semi-transparent photovoltaic (STPV) modules were installed on the southern roofs of the two greenhouses for the control experiment. All PV modules have a mounting angle of $30^{\circ}$, four opaque polysilicon silicon modules occupy $25.9 \%$ of the first greenhouse roof, and three semitransparent monocrystalline silicon modules account for $20 \%$ of the second greenhouse roof.

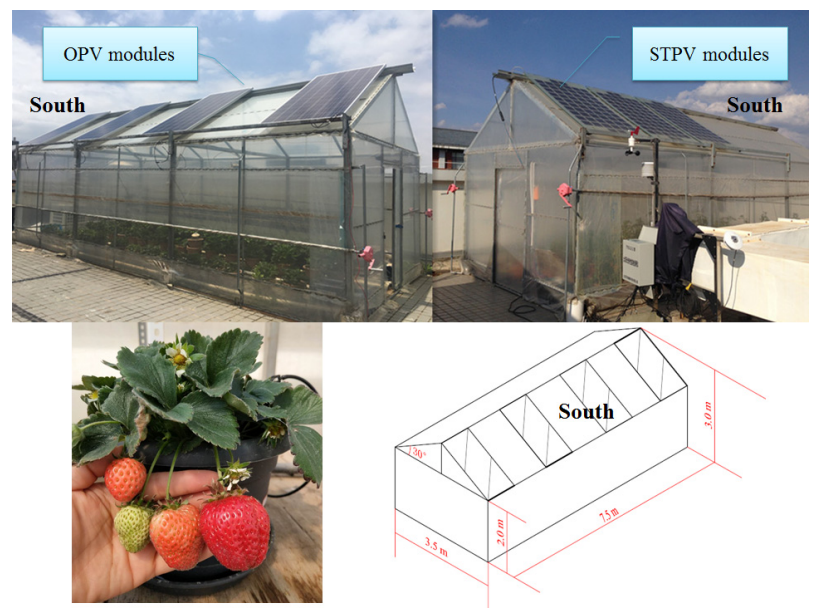

Fig. 1. OPV and STPV greenhouses diagram.

The characteristic parameters of two types of PV modules are shown in Table 1. Before installing PV modules, the annual power generation of PV modules with different tilt angles was simulated by using POLYSUN software. Finally, the tilt angle of $30^{\circ}$ was selected. A pyranometer (produced by Beijing Tianyude Co., Ltd.) was mounted parallel to PV modules plane to measure the incoming solar radiation on them. The greenhouse environmental parameters were controlled by shading of PV modules, including temperature, relative humidity and light. Because of the opacity of OPV modules, in order to meet the lighting needs of plants in greenhouse, the distance between OPV panels was $1.1 \mathrm{~m}$, while the STPV modules with their own spacing (Toughened glass $(6 \mathrm{~mm})+\mathrm{PV}(2.28 \mathrm{~mm})+(125 \times$ $125 \mathrm{~mm})$ sc-Si cells+toughened glass $(6 \mathrm{~mm})$ were continuously installed on the west side of the south roof of the greenhouse.

Table 1. Characteristics of OPV and STPV modules.

\begin{tabular}{ccc}
\hline Characteristic & STPV & OPV \\
\hline $\begin{array}{c}\text { Peak power (Pmax) } \\
\begin{array}{c}\text { Open circuit voltage } \\
\text { (Voc) }\end{array}\end{array}$ & $39.6 \mathrm{~V}$ & $310 \mathrm{~W}$ \\
$\begin{array}{c}\text { Short circuit (Isc) } \\
\text { Voltage (Vmp) }\end{array}$ & $5.65 \mathrm{~A}$ & $85.8 \mathrm{~V}$ \\
Current (Imp) & $33.2 \mathrm{~V}$ & $38.2 \mathrm{~V}$ \\
Weight & $5.12 \mathrm{~A}$ & $8.10 \mathrm{~A}$ \\
& $63.0 \mathrm{~kg}$ & $23.5 \mathrm{~kg}$ \\
& $8.25 \%$ & $17.00 \%$ \\
\hline
\end{tabular}

\subsection{Microclimate monitoring in greenhouses}

The temperature, humidity, and photosynthetically active radiation (PAR) of both greenhouses were measured for both shaded and unshaded data for comparison. As shown in Fig. 2, the temperature, humidity and PAR sensors were placed at a position $1.0 \mathrm{~m}$ above the ground in the greenhouse locations $\mathrm{A}, \mathrm{B}, \mathrm{C}$ and $\mathrm{D}$ where the OPV modules were installed. The accuracy of the test instruments is shown in Table 2.
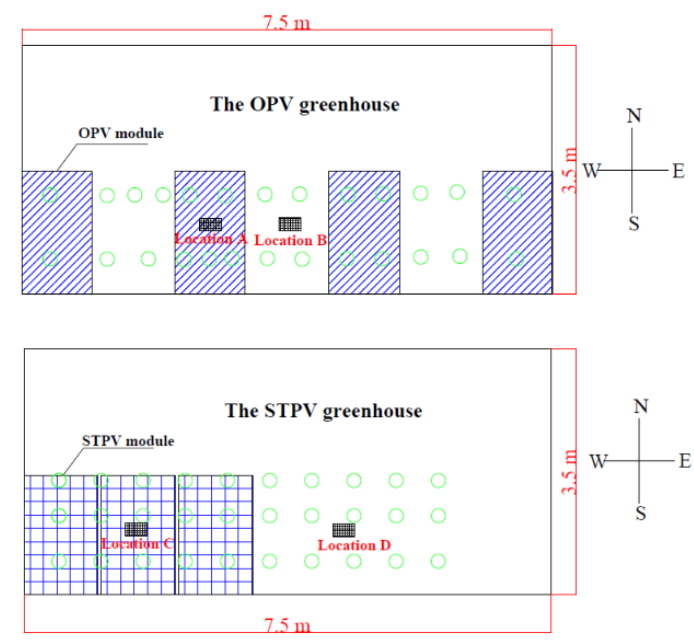

Fig. 2. Top view and sensors location of OPV and STPV greenhouses.

Table 2. The specification of instruments.

\begin{tabular}{cccc}
\hline $\begin{array}{c}\text { Instrument } \\
\text { name }\end{array}$ & Model & $\begin{array}{c}\text { Measurement } \\
\text { range }\end{array}$ & Accuracy \\
\hline Pyranometer & TRT-2-B & $0-2000 \mathrm{~W} \cdot \mathrm{m}^{-2}$ & $\pm 2 \% \mathrm{~W} \cdot \mathrm{m}^{-2}$ \\
Temperature & TH12R- & & \\
and humidity & $\mathrm{EX}$ & $-40-85^{\circ} \mathrm{C}$ & $\pm 0.2^{\circ} \mathrm{C}$ \\
recorder & & $0-100 \%$ & $\pm 2 \%$ \\
\hline
\end{tabular}




\begin{tabular}{lccc}
\hline & $0-2700$ & \pm 1 \\
PAR sensor & GLZ-C & $\mu \mathrm{mol} \cdot \mathrm{m}^{-2} \cdot \mathrm{s}^{-1}$ & $\mu \mathrm{mol} \cdot \mathrm{m}^{-2} \cdot \mathrm{s}^{-1}$ \\
\hline
\end{tabular}

\subsection{Selection and measurements of strawberry sample}

The 'Jingzangxiang' strawberry cultivar, which is derived from the cross between 'Benihoppe' as the male parent and 'Earlibrite' as the female parent was selected for use in PV greenhouses [28]. The survival rate of this cultivar is $98 \%$, moreover, this strawberry cultivar is listed 8 to 20 days earlier than other cultivars under the same planting conditions [29]. In addition, 'Jingzangxiang' strawberry fruit has excellent comprehensive quality, and it is suitable for large-scale production in Kunming [30]. Therefore, the 'Jingzangxiang' strawberry was selected as the experimental cultivar for greenhouse cultivation. There were 30 pots for each greenhouse, accurately planting a strawberry seedling in each pot. All plants had the same cultivation substrate, irrigation and fertilization systems. The experimental design was a randomized block design with two treatments (shaded and unshaded strawberry samples) in each greenhouse.

The measurements of strawberry samples included chlorophyll content in leaves, shortest flowering and fruiting periods, yield per plant, maximum fruit weight and soluble solids content. The chlorophyll content of the leaves was measured by a portable chlorophyll meter $( \pm 1.0$ SPAD) from Shanghai Rong Yan instruments. Co., Ltd, China. The weight and soluble solid content of the fruits were measured by an electronic scales $(0.001 \mathrm{~g})$ and a digital display saccharimeter $( \pm 0.2 \%)$. The data measured in OPV and STPV greenhouses were compared and analysed.

\section{Results and discussions}

\subsection{Electric energy production of OPV and STPV modules on greenhouse roof}

Before installed the PV modules, the annual power generation had been simulated by using POLYSUN software. As shown in Fig. 3, the installation inclination angles of OPV and STPV modules were compared according to $20^{\circ}, 30^{\circ}$ and $40^{\circ}$, respectively. The results showed that the annual power generation of OPV modules was 865,880 and $816 \mathrm{kWh}$, respectively. Correspondingly, the annual power generation of STPV modules was 354,338 and $343 \mathrm{kWh}$. It was theoretically confirmed that the $30^{\circ}$ tilt angle was more suitable for installation in low-latitude subtropical regions, where the PV modules produced the largest annual power generation.

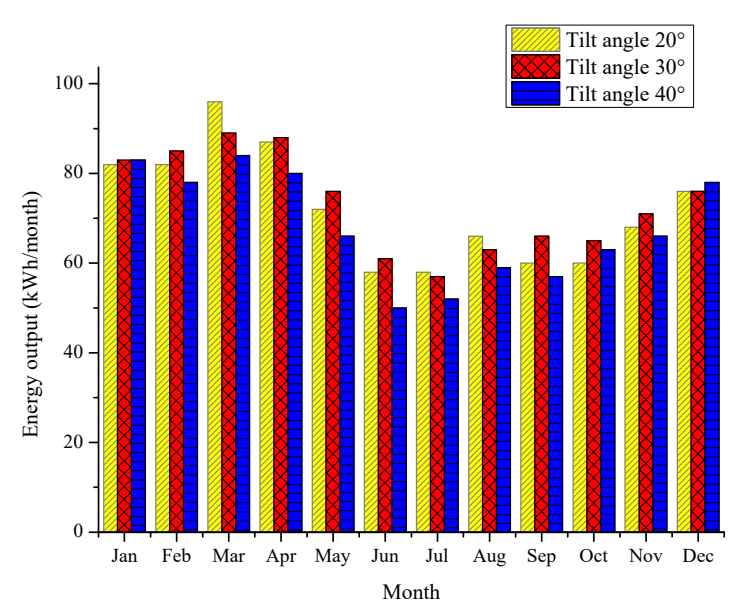

(a) OPVG

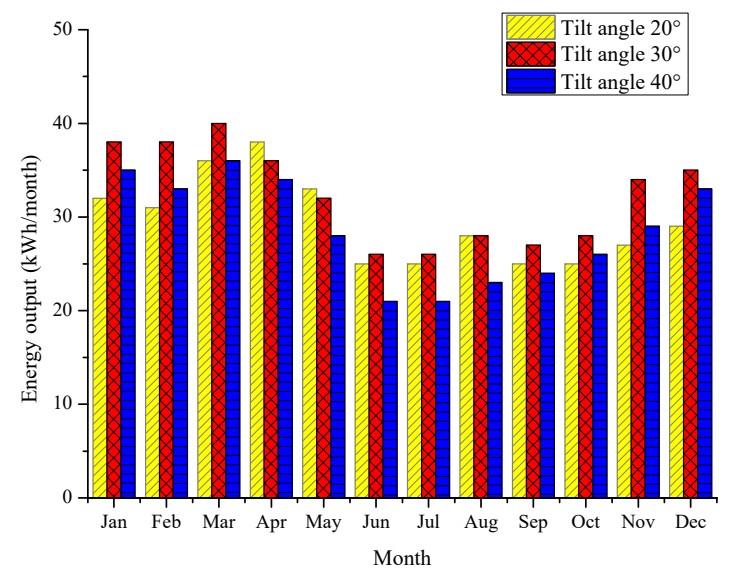

(b) STPVG

Fig. 3. Simulation of electric energy for PV modules by POLYSUN software at different tilt angles.

To further investigate the solar radiation and generated electrical energy received by the greenhouse roof PV modules during the summer, solar radiation was monitored for 30 days (14th July to 12th August 2018) and the total amount of solar radiation per day was analyzed.

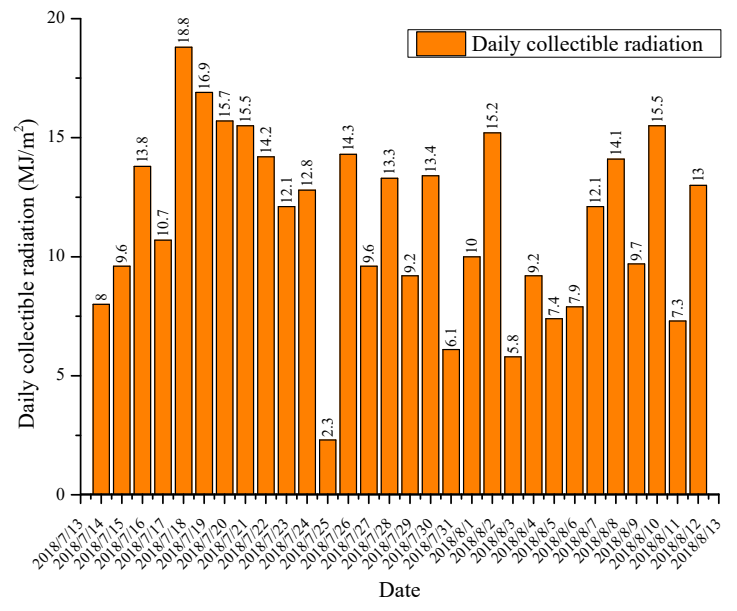


Fig. 4. Daily irradiation per square meter (14th July to 12th August 2018)

As shown in Fig. 4, the daily total irradiation did not reach the ideal value of $20 \mathrm{MJ} / \mathrm{m}^{2}$, and the minimum irradiation was only $2.3 \mathrm{MJ} / \mathrm{m}^{2}$, due to more rainy and cloudy weather in summer in the experimental area. During the sunny weather during the experiment, the maximum daily total radiation received by the PV modules was $18.8 \mathrm{MJ} / \mathrm{m}^{2}$, the daily power generation of OPV module was $0.89 \mathrm{kWh} / \mathrm{m}^{2}$, and the daily power generation of STPV module was $0.43 \mathrm{kWh} / \mathrm{m}^{2}$.

\subsection{Effects of OPV and STPV modules installed on roofs on greenhouse microclimate}

The temperature inside greenhouse was always observed higher than that of the ambient temperature. In contrast, the relative humidity was lower inside the greenhouse than outside particularly during the daytime on sunny days. The PV modules installed on the roof of the greenhouse had an impact on the microclimate in the greenhouse. In order to study the effects of shading, the temperature, humidity and light in the greenhouse were divided into shaded and unshaded parts for data collection and analysis in the typical days from $15^{\text {th }}$ July 2018 to $24^{\text {th }}$ July 2018 .

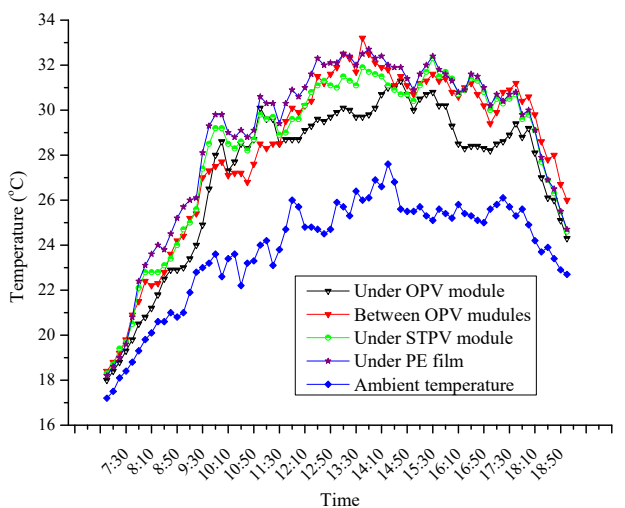

Fig. 5. Comparison of temperature between OPV and STPV greenhouses.

As shown in Fig. 5, when the average ambient temperature was $23.8{ }^{\circ} \mathrm{C}$ in daytime, the unshaded temperature in greenhouse was $28.9^{\circ} \mathrm{C}$, and the shaded temperature in OPV and STPV was 28.4 and $27.3{ }^{\circ} \mathrm{C}$, respectively. When the temperature in the unshaded part of greenhouse reached the highest $32.7{ }^{\circ} \mathrm{C}$, the shaded temperature in OPV and STPV was 29.8 and $31.6{ }^{\circ} \mathrm{C}$, respectively. The temperature under OPV and STPV modules were 2.9 and $1.1{ }^{\circ} \mathrm{C}$ lower than the unshaded temperature in the greenhouses, respectively, at noon in clear weather.

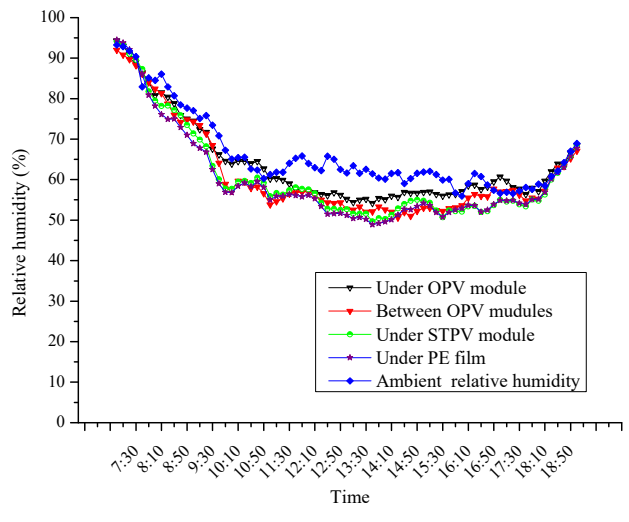

Fig. 6. Comparison of relative humidity between OPV and STPV greenhouses

The relative humidity in the greenhouses generally decreased with increasing temperature. The shading of OPV and STPV modules had less effect on relative humidity. As shown in Fig. 6, the trends between the curves were basically the same, and the difference in relative humidity is not obvious. The minimum relative humidity of $49.2 \%$ in the unshaded part of the greenhouse appeared at 13:50 pm, at which time the relative humidity under OPV and STPV shading was $55.4 \%$ and $50.5 \%$, respectively.

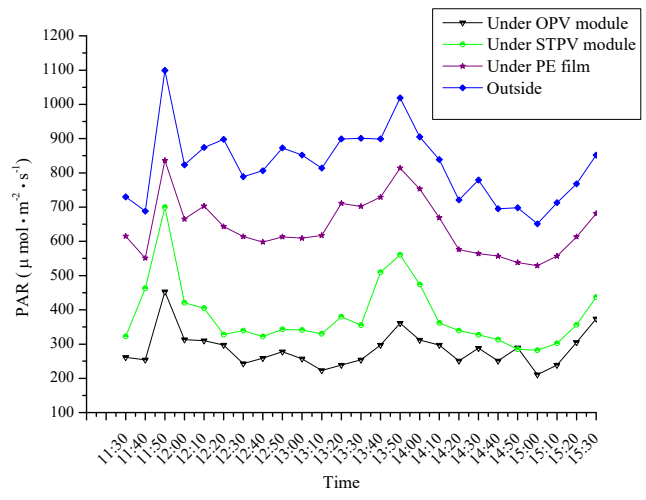

Fig. 7. Light comparison between OPV greenhouse and STPV greenhouse in sunny weather.

Compared to temperature and relative humidity, the effect of shading of PV modules on the light in the greenhouse was most pronounced, especially at noon. Therefore, the data of 11:30-15:30 was selected to compare the PAR. As shown in Fig. 7, compared to the outside PAR curve, the most significantly reduced curve was under the OPV module, and the second reduced curve was under the STPV module. At 13:50 pm, when the outdoor PAR was $1019 \mu \mathrm{mol} \cdot \mathrm{m}^{-2} \cdot \mathrm{s}^{-1}$, the PAR of unshaded part in the greenhouse was $814 \mu \mathrm{mol} \cdot \mathrm{m}^{-2} \cdot \mathrm{s}^{-1}$, the PAR was only $361 \mu \mathrm{mol} \cdot \mathrm{m}^{-2} \cdot \mathrm{s}^{-1}$ under the OPV module, and the PAR was $559 \mu \mathrm{mol} \cdot \mathrm{m}^{-2} \cdot \mathrm{s}^{-1}$ under the STPV module. The average transmittance of PE film was $78.1 \%$, in addition, the transmittance of STPV was $31.7 \%$ lower than PE film, and the transmittance of OPV was $43.5 \%$ lower than PE film. The shading of the PV modules significantly reduced the PAR, avoided excessive burns on the strawberry leaves and provided a 
better light environment for the growth of the strawberry plants.

\subsection{Effects of OPV and STPV shading on strawberry production}

Strawberry growth is susceptible to environmental influences, especially temperature and light. Strawberry samples shaded by PV modules in greenhouse showed better growth than those unshaded samples. The chlorophyll content of strawberry samples in OPV and STPV greenhouses was measured. After 30, 60 and 90 days shaded by PV modules, the chlorophyll content of leaves changed as shown in Fig. 8. The chlorophyll content of strawberry growing period increased gradually, and the chlorophyll content of strawberry shaded by PV module was higher than that of unshaded samples. The chlorophyll content of strawberry samples shaded by OPV was higher than that shaded by STPV. The chlorophyll content of shaded strawberry samples for 90 days was the highest. The chlorophyll content of shaded and unshaded samples in OPV greenhouse were 91.8 and $47.2 \mathrm{mg} / \mathrm{g}$, while the chlorophyll content in STPV greenhouse were 87.6 and $45.0 \mathrm{mg} / \mathrm{g}$.

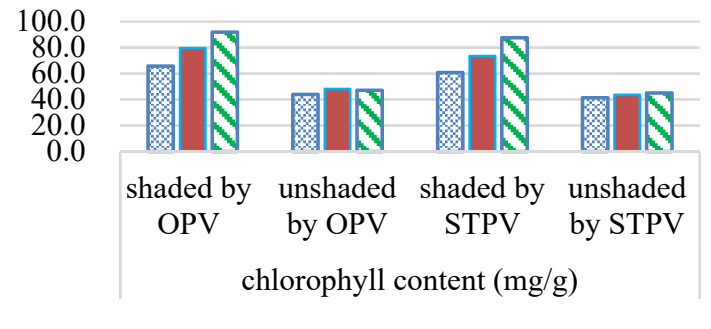

웅 30 days 60 days $\square 90$ days

Fig. 8. Comparison of chlorophyll content in leaves of strawberry samples.

The phenological period of the first batch of strawberries after shading treatment of PV modules was recorded and the yield and quality of strawberry fruits were measured. The results from Table 3 showed that the quality and yield of the strawberry samples under the shade of OPV were better than those of the STPV shade.

Table 3. Phenophase and production parameters of strawberry samples.

\begin{tabular}{lcccc}
\hline & \multicolumn{2}{c}{ OPV greenhouse } & \multicolumn{2}{c}{ STPV greenhouse } \\
& Shaded & Unshaded & Shaded & Unshaded \\
\cline { 2 - 5 } $\begin{array}{l}\text { Flowering } \\
\text { stage (day) }\end{array}$ & 33 & 40 & 35 & 41 \\
$\begin{array}{l}\text { Fruiting } \\
\text { stage (day) }\end{array}$ & 24 & 29 & 28 & 32 \\
$\begin{array}{l}\text { Maximum } \\
\text { weight of } \\
\text { fruit (g) }\end{array}$ & 19.7 & 15.2 & 17.1 & 13.9 \\
$\begin{array}{l}\text { Yield per } \\
\text { plant in the } \\
\text { first fruiting } \\
\text { (g) }\end{array}$ & 69.3 & 55.0 & 62.9 & 47.8 \\
$\begin{array}{l}\text { Soluble } \\
\text { solids } \\
\text { (Brix) }\end{array}$ & 16.4 & 13.1 & & \\
\hline
\end{tabular}

The photos of strawberry fruits in OPV and STPV greenhouses are shown in Fig. 9. It is very obvious that the single fruit of strawberries shaded by PV panels is larger than that of unshaded ones, and strawberries in OPV greenhouse are larger than those in STPV greenhouse.

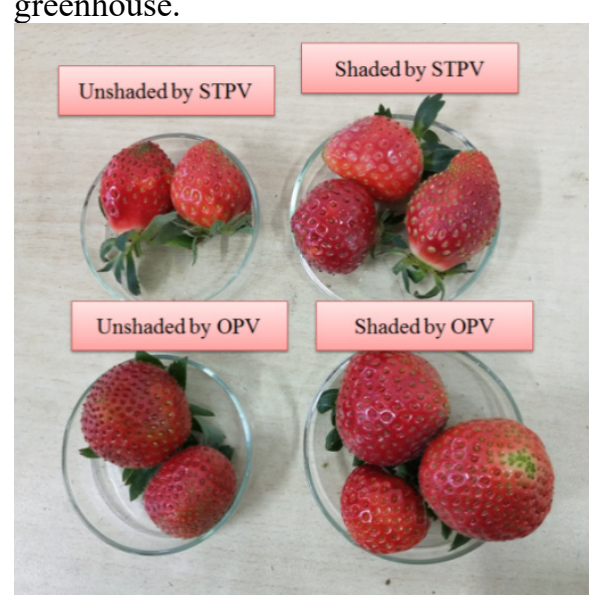

Fig. 9. Photos of strawberry fruits in OPV and STPV greenhouses.

\section{Conclusion}

In this study, two greenhouses with OPV and STPV modules installed at the top of the greenhouse were established. OPV and STPV modules accounted for $25.9 \%$ and $20 \%$ of the roof area, respectively. The annual power generation of OPV and STPV modules was simulated. It was proved that proper shading of PV modules would not affect the growth of strawberry plants in greenhouse, and could also improve the yield and quality of strawberry fruits. The results showed that strawberry samples in OPV greenhouse were better than those in STPV greenhouse in growth and production, and strawberry samples under OPV component shade showed a better development trend.

\section{Acknowledgement}

This work was supported by the Collaborative Innovation Centre of Research and Development of Renewable Energy in the southwest area in China (No. 05300205020516009) and Research of cooperation mechanism and coordinated control of photovoltaic greenhouse system based on the optimum photosynthetic efficiency of crops (No.51867022).

\section{References}

1. G. Trypanagnostopoulos, A. Kavga, M. Souliotis, Y. Tripanagnostopoulos, Greenhouse performance results for roof installed photovoltaics, RENEWABLE ENERGY, 111(2017)724-731.

2. A. Vadiee, V. Martin, Energy management in horticultural applications through the closed greenhouse concept, state of the art, Renewable and Sustainable Energy Reviews, 16(2012)5087-5100. 
3. A. Marucci, A. Cappuccini, Dynamic photovoltaic greenhouse: Energy efficiency in clear sky conditions, APPLIED ENERGY, 170(2016)362-376.

4. B. Valle, T. Simonneau, F. Sourd, P. Pechier, P. Hamard, T. Frisson, M. Ryckewaert, A. Christophe, Increasing the total productivity of a land by combining mobile photovoltaic panels and food crops, APPLIED ENERGY, 206(2017)1495-1507.

5. H. Dinesh, J.M. Pearce, The potential of agrivoltaic systems, Renewable and Sustainable Energy Reviews, 54(2016)299-308.

6. H. Yildizhan, Energy, exergy utilization and $\mathrm{CO} 2$ emission of strawberry production in greenhouse and open field, ENERGY, 143(2018)417-423.

7. A. Marucci, D. Monarca, M. Cecchini, A. Colantoni, A. Cappuccini, Analysis of internal shading degree to a prototype of dynamics photovoltaic greenhouse through simulation software, Journal of Agricultural Engineering, 46(2015)144-150.

8. M. Cossu, A. Yano, Z. Li, M. Onoe, H. Nakamura, T. Matsumoto, J. Nakata, Advances on the semitransparent modules based on micro solar cells: First integration in a greenhouse system, APPLIED ENERGY, 162(2016)1042-1051.

9. Y.C. Kuo, C.M. Chiang, P.C. Chou, H.J. Chen, C.Y. Lee, C.C. Chan, Applications of building integrated photovoltaic modules in a greenhouse of Northern Taiwan, Biobased Mater. Bioenergy, 6(2012)721727.

10. A. Yano, M. Onoe, J. Nakata, Prototype semitransparent photovoltaic modules for greenhouse roof applications, BIOSYSTEMS ENGINEERING, 122(2014)62-73.

11. R. Gupta, G.N. Tiwari, A. Kumar, Y. Gupta, Calculation of total solar fraction for different orientation of greenhouse using 3D-shadow analysis in Auto-CAD, ENERGY AND BUILDINGS, 47(2012)27-34.

12. S. Castellano, P. Santamaria, F. Serio, Solar radiation distribution inside a monospan greenhouse with the roof entirely covered by photovoltaic panels, Journal of Agricultural Engineering, 47(2016)1-6.

13. M. Cossu, A. Cossu, L. Ledda, G. Urracci, A. Sirigu, L. Murgia, A. Pazzona, A. Yano, An algorithm for the calculation of the light distribution in photovoltaic greenhouses, SOLAR ENERGY, 141(2017)38-48.

14. A. Yano, M. Kadowaki, A. Furue, N. Tamaki, T. Tanaka, E. Hiraki, Y. Kato, F. Ishizu, S. Noda, Shading and electrical features of a photovoltaic array mounted inside the roof of an east-west oriented greenhouse, BIOSYSTEMS ENGINEERING, 106(2010)367-377.

15. M. Kadowaki, A. Yano, F. Ishizu, T. Tanaka, S. Noda, Effects of greenhouse photovoltaic array shading on Welsh onion growth, BIOSYSTEMS ENGINEERING, 111(2012)290-297.
16. R.H.E. Hassanien, M. Li, F. Yin, The integration of semi-transparent photovoltaics on greenhouse roof for energy and plant production, RENEWABLE ENERGY, 121(2018)377-388.

17. L.G.L.D. H. Marrou, Microclimate under agrivoltaic systems: Is crop growth rate affected in the partial shade of solar panels? AGRICULTURAL AND FOREST METEOROLOGY, (2013)117-132.

18. C. Dupraz, H. Marrou, G. Talbot, L. Dufour, A. Nogier, Y. Ferard, Combining solar photovoltaic panels and food crops for optimising land use: Towards new agrivoltaic schemes, RENEWABLE ENERGY, 36(2011)2725-2732.

19. H. Marrou, J. Wery, L. Dufour, C. Dupraz, Productivity and radiation use efficiency of lettuces grown in the partial shade of photovoltaic panels, EUROPEAN JOURNAL OF AGRONOMY, 44(2013)54-66.

20. H.A. Ahemd, A.A. Al-Faraj, A.M. Abdel-Ghany, Shading greenhouses to improve the microclimate, energy and water saving in hot regions: A review, SCIENTIA HORTICULTURAE, 201(2016)36-45.

21. F. Giampieri, J.M. Alvarez-Suarez, M. Battino, Strawberry and human health: effects beyond antioxidant activity, J. Agric. Food Chem, 18(2014)3867-3876.

22. V.C. Chaves, EuniceCalvete, F.H. Reginatto, Quality properties and antioxidant activity of seven strawberry (Fragaria $\mathrm{x}$ ananassa duch) cultivars, SCIENTIA HORTICULTURAE, 225(2017)293298.

23. B. Khoshnevisan, S. Rafiee, H. Mousazadeh, Environmental impact assessment of open field and greenhouse strawberry production, EUROPEAN JOURNAL OF AGRONOMY, 50(2013)29-37.

24. B. Khoshnevisan, S. Rafiee, H. Mousazadeh, Environmental impact assessment of open field and greenhouse strawberry production, EUROPEAN JOURNAL OF AGRONOMY, 50(2013)29-37.

25. A. Sønsteby, K.A. Solhaug, O.M. Heide, Functional growth analysis of 'Sonata' strawberry plants grown under controlled temperature and daylength conditions, SCIENTIA HORTICULTURAE, 211(2016)26-33.

26. F. Martínez, J.A. Oliveira, E.O. Calvete, P. Palencia, Influence of growth medium on yield, quality indexes and SPAD values in strawberry plants, SCIENTIA HORTICULTURAE, 217(2017)17-27.

27. E.F. Durner, Photoperiod and temperature conditioning of 'Sweet Charlie' strawberry (Fragaria $\times$ ananassa Duch.) plugs enhances offseason production, SCIENTIA HORTICULTURAE, 201(2016)184-189.

28. Y. Zhang, G. Wang, L. Chang, J. Dong, C. Zhong, L. Wang. A new strawberry caltivar 'Jingzangxiang', Research progress of strawberry,Beijing,2015.

29. L.F. Song, M.Y. Hua, Y.N. Tong, X.L. Yang, Performances of Beijing strawberry varieties in 
Tianjin area, Journal of Anhui Agricultural Sciences, 44(2016)50-52.

30. S.Y. Chen, Z.W. Luo, H. Wan, S. Wang, B. Tao, Introduction experiment of four Beijing strawberry varieties cultivated in open field in Kunming Yiliang county, Chinese Horticulture Abstracts, (2017)7-8. 